Why Am I Learning This? Using Everyday Examples in Engineering to Engage Female (And Male) Students in the Classroom

Dr. Tonya Lynn Nilsson P.E., Santa Clara University 


\section{Why Am I Learning This? Using Everyday Examples in Engineering to Engage Female (And Male) Students in the Classroom}

Too often new engineering concepts are presented to students with little to no indication of where these concepts exist in our day to day lives. If examples are provided, they are commonly applications that are still beyond the everyday experience of our students, e.g. bending of beams in a loaded building versus bending of a skateboard carrying a rider. Educational studies indicate that learning and understanding are enhanced if the learner can tie new concepts to existing knowledge, especially knowledge they have gained experientially. To promote improved student performance and retention, NSF's Research on Gender in Science and Engineering funded ENGAGE to increase college and university use of three research strategies found to improve outcomes for all students but particularly for female students. One of these strategies is the incorporation of Everyday Examples in Engineering $\left(\mathrm{E}^{3} \mathrm{~s}\right)$ into math, science and engineering instruction.

This work presents the results of using $\mathrm{E}^{3} \mathrm{~s}$ in a sophomore-level Mechanics of Materials course. Student performance on exam questions from three sections that did not receive instruction using $\mathrm{E}^{3} \mathrm{~s}$ was compared with student performance from five sections taught using $\mathrm{E}^{3} \mathrm{~s}$. The only change in the course instruction was the replacement of typical textbook examples to everyday examples. All students included in the study were taught by the same instructor. Long-term retention of course concepts was also reviewed by implementing a concept quiz on the first day of a junior level course that students take anywhere from six to nine months after the completion of the Mechanics of Materials course. The concept quiz has been administered three times: once to students from the three sections taught without $\mathrm{E}^{3} \mathrm{~s}$ and twice to include the students from the five sections taught with $\mathrm{E}^{3} \mathrm{~s}$.

Results of this work show that both student exam performance and material retention improved as a result of using proven $\mathrm{E}^{3} \mathrm{~s}$ regardless of gender. Course topics where the existing teaching methods already resulted in solid student exam performance saw the least impact on exam grades from the inclusion of $\mathrm{E}^{3} \mathrm{~s}$, but student retention in these topics was improved. This would suggest that faculty would see the greatest immediate gains by including $\mathrm{E}^{3} \mathrm{~s}$ in those areas where their students have historically had poor performance. However, for long-term material retention, proven $\mathrm{E}^{3} \mathrm{~s}$ should be included whenever possible to introduce new engineering concepts. Finally, student interest in course material was shown to increase slightly for male students and significantly for female students when $\mathrm{E}^{3} \mathrm{~s}$ where incorporated in the course.

\section{Introduction}

Educational research repeatedly indicates that new material linked to a familiar concept is more likely to be understood and retained by a learner, especially if the existing knowledge was learned experientially. ${ }^{1,2}$ Some researchers go as far as stating that new material that is not linked to a prior experience will either be stored in short-term memory and soon forgotten or simply not learned at all. ${ }^{3}$ Linking new ideas to familiar concepts has been found to reduce anxiety and fear in the learner. ${ }^{4,5}$ This not only can improve learning, but students are more likely to take an interest in a subject matter they understand. The educational community refers to these familiar ideas as "everyday examples". 
The use of everyday examples has become common in textbooks, at least according to the publishers. A cursory review of the marketing descriptions of science and engineering textbooks will undoubtedly find that many describe the use everyday examples to make the content more accessible to students. $6,7,8,9,10,11,12,13$ While not every textbook is truly using examples that relate to the everyday experience of college students, the adoption of everyday examples in textbooks is occurring at a much faster rate than the adoption in the classroom. Unfortunately, many of these examples may be more closely aligned with the male student's experience versus the female student's: race cars, motors, football. An effective everyday example is something that is common in the everyday life of all the students in the class.

To help address this shortcoming, NSF's Research on Gender in Science and Engineering funded ENGAGE, which has partnered with over 70 universities to "increase the capacity of engineering schools to retain undergraduate students by facilitating the implementation of three researchbased strategies to improve student day-to-day classroom and educational experience." ${ }^{34}$ These strategies include: "integrating into coursework, Everyday Examples in Engineering $\left(\mathrm{E}^{3} \mathrm{~s}\right)$; improving student spatial visualization skills; and improving and increasing faculty-student interaction."14 These strategies have been shown to improve learning outcomes for all students but particularly for female students.

Incorporating $\mathrm{E}^{3}$ s into a course enables the student to link the course material to a familiar concept. As stated earlier, this familiarity can improve student interest and lessen student fear and anxiety, which improves student self-efficacy. This is especially important for female students as research has shown that self-efficacy relates to female students' persistence rates. ${ }^{15}$ In fact, simply improving student interest in the subject matter is known to improve student persistence for all students. ${ }^{16}$

This paper reports the results of implementing $E^{3} s$ in a sophomore level Mechanics of Materials course taught at a private, primarily undergraduate institution. Civil engineering students composed close to 33 percent of the overall course enrollment and mechanical engineering students composed the remainder. Over the course of three years, eight sections of the class were taught by the same instructor: three sections prior to the implementation of $\mathrm{E}^{3} \mathrm{~s}$ and five sections with $E^{3}$ s. Both short-term and long-term material retention was evaluated. Short-term retention was compared using student performance on course examinations. Long-term retention was determined using a short quiz on the first day of class of a required course for the junior-level mechanical engineering students. Due to the curriculum structure, students do not enroll in the junior level course until six to nine months after completing Mechanics of Materials. Student self-perception surveys were also conducted at the end of the course and students were asked to rate their interest in the course material on a five point Likert scale and to indicate if the course activities increased their overall material interest.

\section{Everyday Examples in Engineering}

Engineering students are regularly introduced to new and seemingly unfamiliar topics in their engineering courses. Students do not readily link what they are learning to the immediate world around them even though most engineering concepts are observable in our daily lives. Everyday Examples in Engineering make the new topics accessible to students and provide context as to 
why they are learning the material and how it relates to their lives. Everyday examples are only effective if they are relevant to the life experience to date of the college student. Engineering instructors with years of experience must reflect back to their level of experience and knowledge as an undergraduate. For example, axial loading and deformation of composite members is an early topic in the Mechanics of Materials course. A common textbook example for this topic, which many experienced engineers would consider an everyday example, is a concrete/steel composite column of either concrete reinforced with steel rebar or a steel pipe in-filled with concrete. However, most college sophomores are not familiar with construction or design with concrete. Further, the students are not able to personally experience how much a piece of steel would deform under a given load versus an unreinforced concrete member or how the two materials behave relative to each other when they are a composite member.

Consider alternatively an $\mathrm{E}^{3}$ developed by Eann Patterson, author of the Real Life Examples booklets. ${ }^{17}$ Students are all familiar with smart phone earbuds and the cables that attach them to the phone, see Figure 1. The cable is a composite material made of copper wire with a plastic coating. Patterson suggests walking into class wearing a pair of earbuds that are attached to a smart phone or mp3 player. Ask the students if they have every dropped their electronic device only to have it "caught" by the cable, which, under load, is an axially loaded composite member. Since coated wire, stripped wire and heat-shrink tubing (the basic equivalents of the earbud cable components) are readily available, short sections of each can be passed out to students to

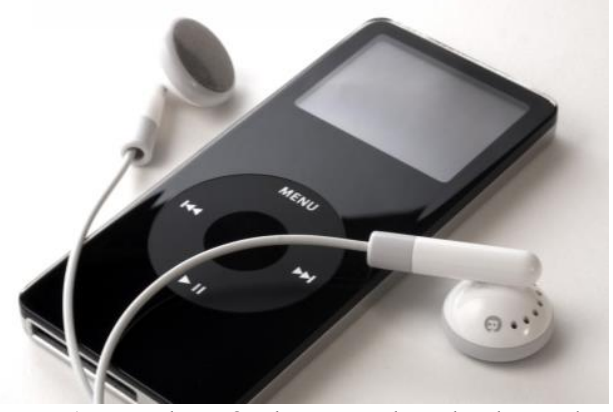

Figure 1: Ipod mp3 player and earbuds. The earbud cable can be an $\mathrm{E}^{3}$ demonstration of an axially loaded composite member. Source:

http://wallpaperscraft.com/download/ipod_player_headp hones_82447/1920x1080 allow them to experientially compare the materials' stiffness, observe the composite behavior of the coated wire, and make estimates of the percent of the load carried by the copper wire versus the plastic coating. Finally a numerical example can be solved using the mass of the phone or mp3 player and the estimated cross-sectional areas and moduli of elasticity of the plastic tubing and copper.

The above example is both familiar and relevant to the students. Further, incorporating pieces of the cable's components for student investigation provides an opportunity for students to build knowledge that is gained experientially. This earbud cable example and in-class demonstration was one of four $\mathrm{E}^{3} \mathrm{~s}$ used in this study and was found to have the most dramatic effect on student learning.

The three additional $\mathrm{E}^{3} \mathrm{~s}$ implemented in the Mechanics of Materials course as part of this study are described below. The first two can also be found in Patterson's booklet ${ }^{17}$. The final $\mathrm{E}^{3}$ was developed by the author.

Skateboards as transverse beams in bending. Not only are all the students familiar with skateboards, as shown in Figure 2, it is likely that more than one student will arrive to class via their skateboard providing the instructor with a handy visual demonstration. A quick survey of the students can determine if anyone has broken a skateboard or witnessed 
someone else breaking their skateboard. This allows the instructor to inquire: why the board broke, what type of stresses was the board under, and if the rider's foot position on the board change the stresses. This direction of inquiry sets up a real life need to determine both the loads and stresses in the skateboard. The skateboard $\mathrm{E}^{3}$ can now be used to demonstrate and describe the need for:

- drawing shear and moment diagrams,

- determining bending stresses,

- determining shear stresses,

- determining bending stresses in a composite members as some skateboards are made of layers of different materials, and

- determining the deflections of beams.

Overpasses and railroad rails for axial deformation due to temperature. A quick show of hands would highlight that today's students are all familiar with the tire noise made as cars drive across the expansion joints found on overpasses. From their previous knowledge, the students can also identify that these joints are needed to resist expansion due to temperature increases. But what if the gap is too small for the expansion? While we don't often hear of concrete bridges buckling due to heat waves, rail road lines do and the internet is full of pictures of the results. Using the cross-sectional area and modulus of elasticity of the steel rails, student can determine the amount of expected elongation.

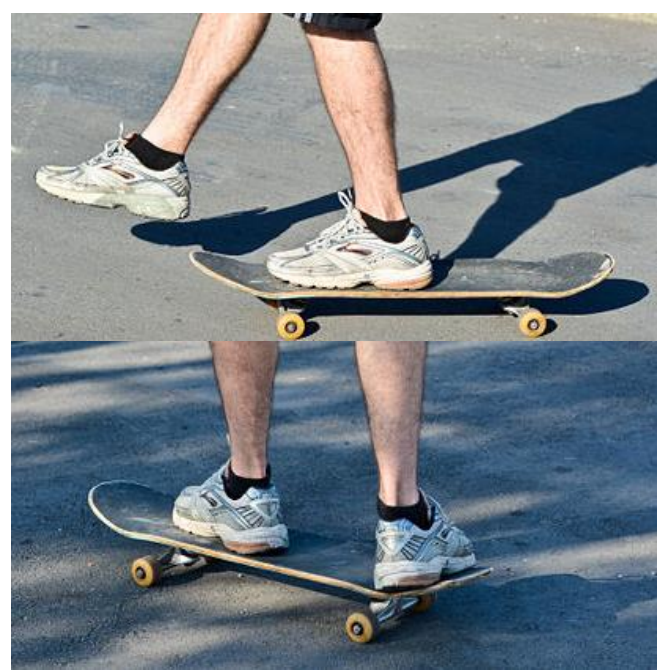

Figure 2: Skateboard with various loadings as an $\mathrm{E}^{3}$ for a transverse beam in bending. Source: http://www.wikihow.com/Ride-up-a-Curb-on-aSkateboard

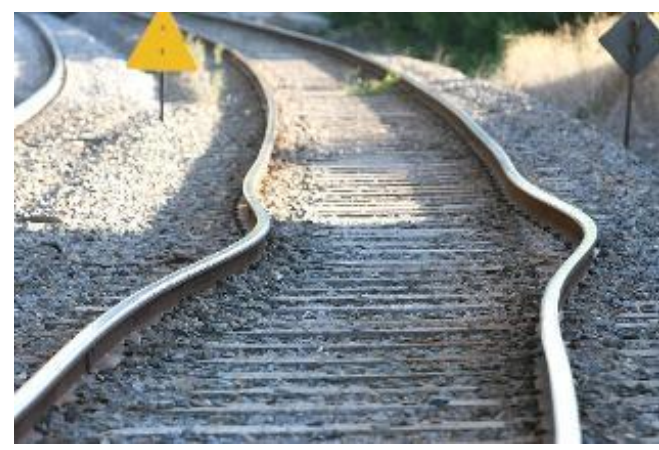

Figure 3: Buckled (or sun kinked) railroad rails provide a real life example of stresses due to thermal expansion.

Source: http://www.couriermail.com.au While students may not have ever ridden a train, railroads are so common that students are familiar with them and they provide real-life context to why the students are learning about elongation due to temperature and the stresses that can develop if the extension is restricted.

Bicycle handlebars and stem to demonstrate combined loading. Many students struggle with determining the support reactions caused by a single load in a three-dimensional space. Further, if this load causes multiple moments and forces at the support, calculating the stresses due to the multiple moments and forces can be overwhelming. Often the example problems in textbooks used to illustrate combined loadings are either a simple bent bar with no recognizable purpose or machinery parts that students have no experience with. Students are familiar with bicycles and their components. So for this $\mathrm{E}^{3}$, a bicycle is brought into class and a student is asked to push on the handlebars while the bike is held in place. Figure 4 , showing a biked locked in place, has also been shown when a bike was not available. The students are asked to think about and describe how a load moves from the handlebars into the stem and then the head tube of the bike if the handlebars cannot turn and the bike is not allowed to tip or roll. Students are then provided a handout with the drawn image in Figure 4 
and asked to determine the components of the shown force $\mathrm{F}$ and any moments it would cause on the stem's cross-section at the height of point A. Once the students, have determined the forces on the cross-section at point A, they are asked to identify all the normal and shear stresses acting at point $\mathrm{A}$, the formulas for those stresses and the acting directions of the stresses. To provide the students with a physical model that matched the drawn image in Figure 4, the author worked with the campus police department to obtain eight broken down bicycles that were collected at the end of the school year as abandoned bikes. With the help of the campus machine shop, the stems were removed from the bike head tubes, machined at the base to add threads and then screwed into common floor-flange pipe fittings that were each mounted on a plywood base.

\section{Course Enrollment and Course Format}

During the 2010-2011 school year, three sections of the Mechanics of Materials course were taught: one in the Winter 2011 quarter (W2011) and two in the Spring 2011 quarter (S2011-1 \& S2011-2). Everyday Examples in Engineering were not used in these sections. During the 2011-2012 and the 2012-2013 school years, five additional sections of Mechanics of Materials were taught that all incorporated $E^{3}$ s: two in
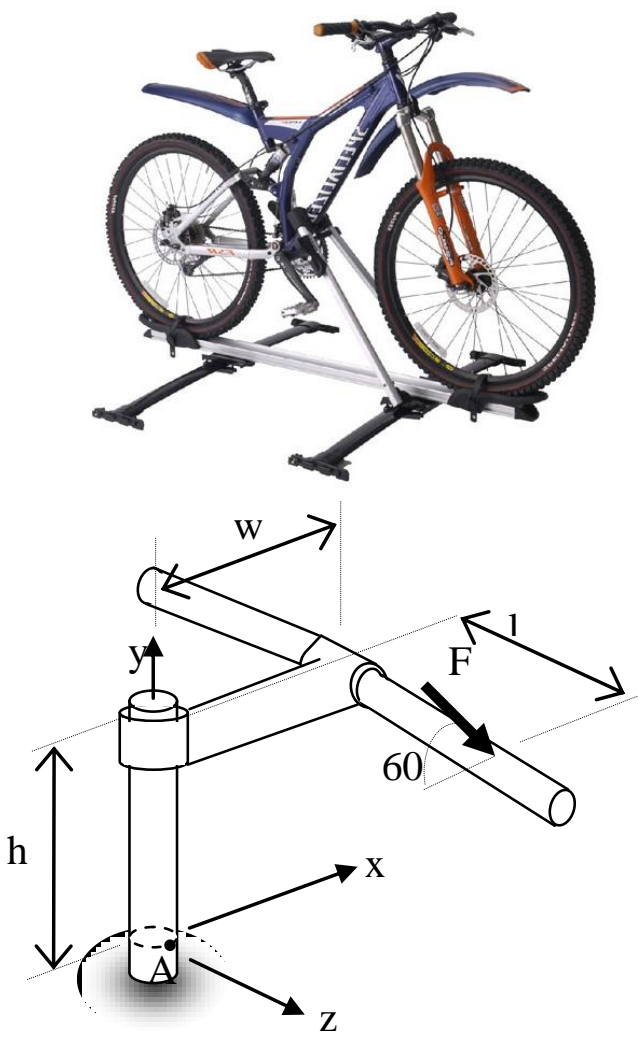

Figure 4: Bicycle handles bars and stem provide a familiar example for combined loading.

Bike Photo Source:

http://autoanything.wordpress.com/category/productreview/jeep-accessories/

Winter 2012 (W2012-1 \& W2012-2), one in Spring 2012 (Spring 2012), one in Winter 2013 (W2013) and one in Spring 2013 (S2013). Total course enrollments and enrollments by gender are shown in Table 1 . In the three quarters taught without $\mathrm{E}^{3} \mathrm{~s}$, there were a total of 20 females and 42 males enrolled. In the five terms taught with $\mathrm{E}^{3} \mathrm{~s}, 55$ females and 149 males were taught.

As a means to study the effect of instructional changes in the course, final exams are not returned to students, allowing the use of the same or similar problems each quarter to compare student performance. During a single quarter, if there are multiple final exam periods occurring on different days, different Table 1: Total course enrollments for the eight sections taught. The 2011 sections were not taught with $\mathrm{E}^{3} \mathrm{~s}$.

\begin{tabular}{|c|c|c|c|}
\hline $\begin{array}{c}\text { Count of } \\
\text { Students } \\
\text { Enrolled in the } \\
\text { Section }\end{array}$ & Total & Female & Male \\
\hline W2011 & 30 & 11 & 19 \\
\hline S2011-1 & 17 & 4 & 13 \\
\hline S2011-2 & 15 & 5 & 10 \\
\hline W2012-1 & 45 & 17 & 28 \\
\hline W2012-2 & 35 & 12 & 23 \\
\hline S2012 & 40 & 6 & 34 \\
\hline W2013 & 36 & 13 & 23 \\
\hline S2013 & 48 & 7 & 41 \\
\hline
\end{tabular}
exams are given but often the same concept with a question of a similar level of difficulty is tested. During the Winter and Spring quarters of 2013, two examination period options were 
provided to the students although there was only one section each quarter, which meant two different exams were used both quarters. The results of these two examination periods are denoted with an ' $a$ ' or ' $b$ ' in the results, e.g. W2013-a and W2013-b.

Table 2 shows the number of students that sat for each exam period. As seen in the table, the alternative exam times, 'b', in Winter and Spring Quarters of 2013 had the smallest number of students.

The course examinations were developed based on the published course and topic learning objectives. Well-defined learning objectives are published and linked to every topic taught in the course. Students are instructed that they are expected to be able to achieve the level of ability defined by the learning objective and course exams are written based on the published objectives. Numerous activelearning techniques, physical models and pictures are included in the course instruction to engage students and help them achieve the learning objectives. The following are examples of typical learning objectives taken directly from the course syllabus and lesson sheets that align with the $\mathrm{E}^{3}$ s discussed in this paper.

Students will be able to:

- Determine thermal expansion in a structural member.

- Calculate stresses, if any, due to thermal expansion.

- Determine stresses in a statically indeterminate axially loaded member, which includes composite members.

- Compute the shear and moment magnitudes at any location along the length of a beam due to transverse loading using shear and moment diagrams.

- Calculate all acting stresses at a point due to combined loading.

In-class activities and homework problems are designed to give students opportunities to practice their skills in meeting given objectives. Prior to exams, students are instructed to verify they are able to do all the activities described by the objectives corresponding to the lessons covered on the exam. For the final exams used in this study, students were told to review all the course learning objectives as the exams were comprehensive. Because the students have been given clear direction as to the level of understanding expected of them and have had opportunities to practice and assess their skills through homework and class activities, and because the exam is written to the skill level of the published learning objectives, curving of exam results is not necessary. In fact, if every student met every learning objective then every student would receive an A on the exam. More realistically, the class averages on any given problem will hopefully range between 75 and 85 percent. The student performance percentages shown in the following section are the actual class averages and have not been curved or modified. 


\section{The Effect of Everyday Examples in Engineering on Student Performance}

Both short-term and long-term material retention of the $\mathrm{E}^{3}$ topics was reviewed. The short-term retention is shown by student performance on course exams. To assess the long-term retention, short pop-quizzes have been administered on the first day of the mechanical engineering Machine Design course. This required course for all mechanical engineering students is offered during the winter quarter of the junior year. The Mechanics of Materials course, a prerequisite to Machine Design, must be taken during the winter or spring quarters of the sophomore year. The quiz includes conceptual questions on moment diagrams, combined loading, and axially-loaded composite members.

The short-term retention results shown in Figures $5-8$ show the average student score and standard deviation on exam problems that addressed the four course topics taught incorporating the Everyday Examples in Engineering. Data is displayed per exam session. A vertical line has been drawn to delineate the quarters taught with or without $\mathrm{E}^{3} \mathrm{~s}$. Due to the small sample size in some of the exam sections, Figures $9-12$ show combined results that compare all the students

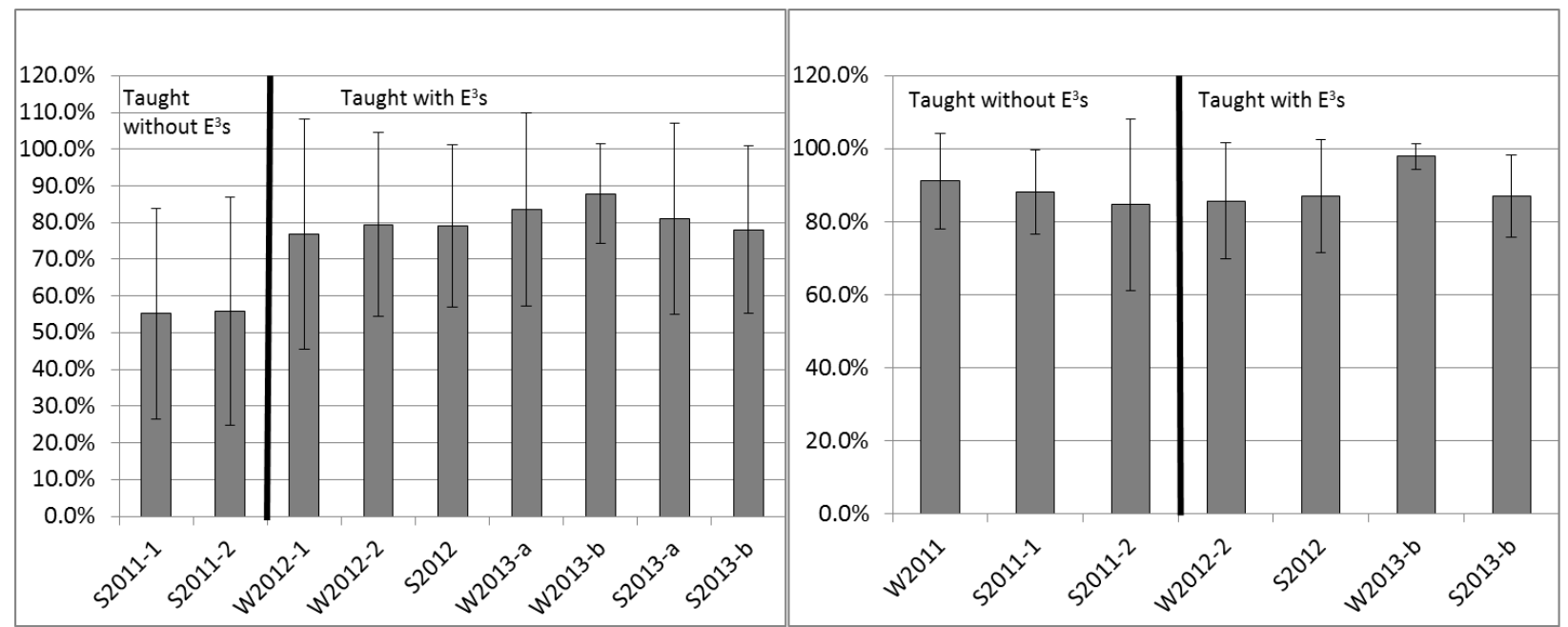

Figure 5: Average student exam score on a Composite Axially- Loaded Member
Figure 6: Average student exam score on Drawing Shear and Moment Diagrams

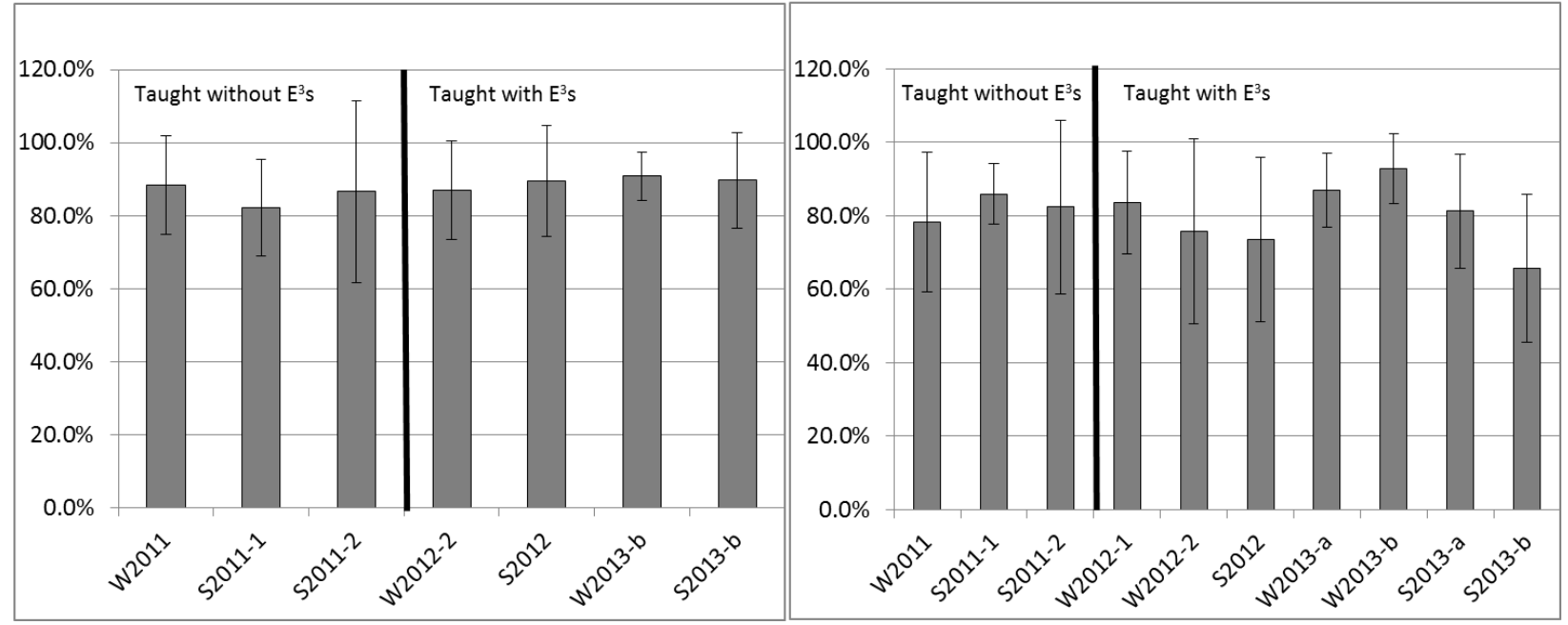

Figure 7: Average student exam score on Behavior Due to Thermal Expansion
Figure 8: Average student exam score on Stresses Due to Combined Loading 
who learned the material without $\mathrm{E}^{3} \mathrm{~s}$ to those student who learned the material with $\mathrm{E}^{3} \mathrm{~s}$. These figures also break out male and female student performance. Table 3 provides the results of the retention quizzes. Forty-four mechanical engineering students who were taught the tested concepts without $\mathrm{E}^{3} \mathrm{~s}$ where given the retention quiz at the start of the Winter 2012 quarter, while a total of 101 mechanical engineering students who learned the material using $\mathrm{E}^{3} \mathrm{~s}$ were tested in either the Winter 2013 or Winter 2014 quarter.

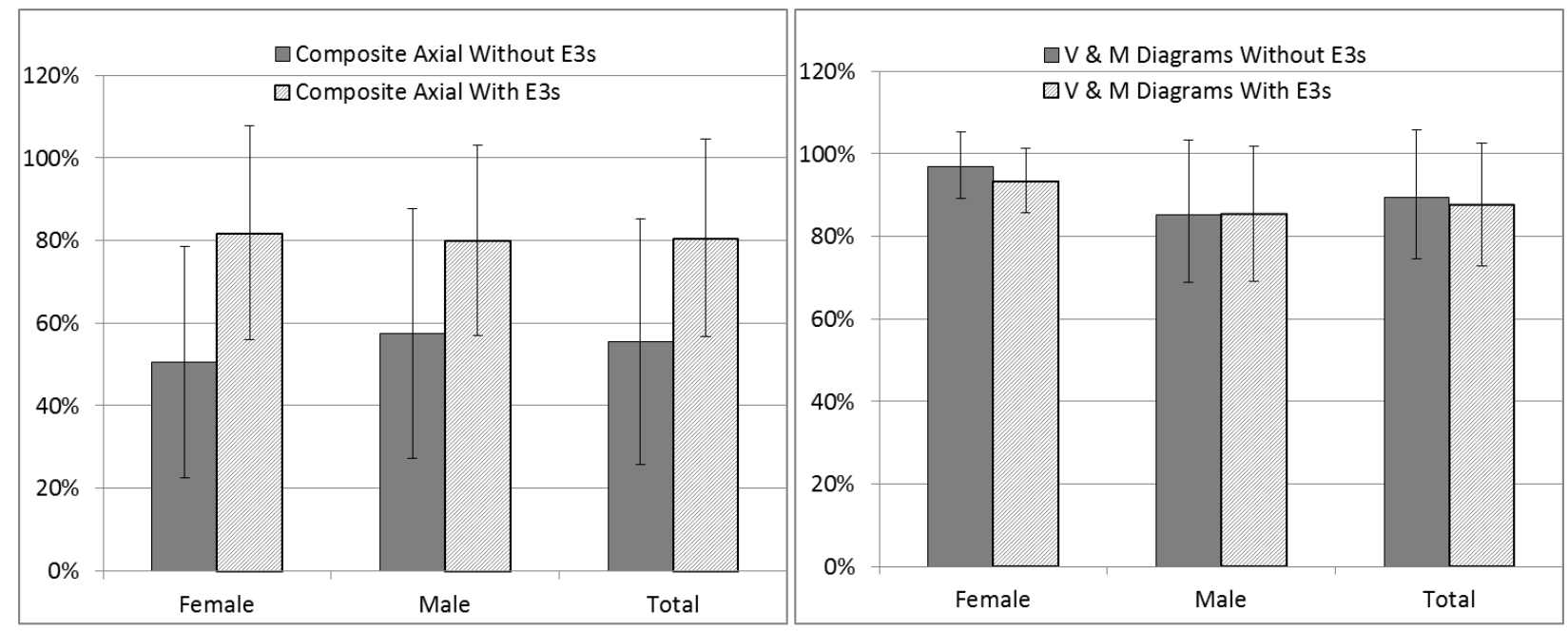

Figure 9: Average student exam score by gender on a Composite Axially- Loaded Member

Figure 10: Average student exam score by gender on Drawing Shear and Moment Diagrams

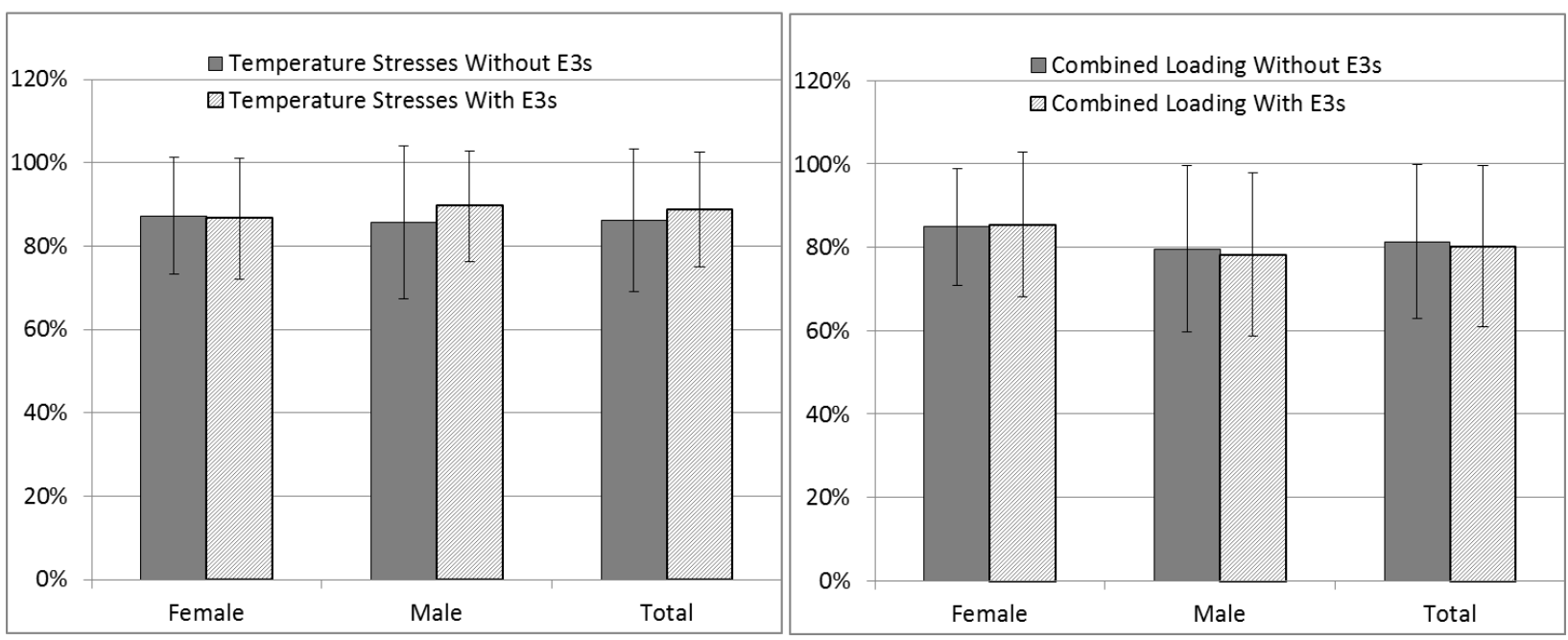

Figure 11: Average student exam score by gender on Behavior Due to Thermal Expansion

Figure 12: Average student exam score by gender on Stresses Due to Combined Loading

The most dramatic learning gains were seen for the topic of composite axially-loaded members shown in Figures 5 and 9. Prior to using the earbud cable $E^{3}$, the average exam score for this topic was approximately 55 percent, with female students averaging 50 percent. The students struggled with the idea that the two composite materials experience the same axial deformation: a key concept for this topic. After incorporating the earbud cable demonstration that included the physical sections of coated wire, stripped wire and heat-shrink tubing that allowed the 
students to compare deformation behavior, the overall class exam averages increased by 25 percent, while the average for female students increased by almost 32 percent. This topic still shows a high standard deviation among all the students, but the overall standard deviation dropped by six percent for all students and two percent for female students. In addition, Table 3 indicates that number of students who retained this material long-term retention increased by sixteen percent.

Table 3: Percent of students answer questions correctly on a long-term retention quiz given to students approximately six to nine months after learning the tested subject using an $\mathrm{E}^{3}$.

\begin{tabular}{|c|c|c|c|c|c|c|}
\hline \multirow{2}{*}{$\begin{array}{c}\text { Topics } \\
\text { Taught } \\
\text { Using E's }\end{array}$} & \multirow{2}{*}{$\begin{array}{c}\text { Mechanics } \\
\text { of Materials } \\
\text { Taken }\end{array}$} & \multirow{2}{*}{$\begin{array}{l}\text { Quiz } \\
\text { Given }\end{array}$} & \multirow{2}{*}{$\begin{array}{c}\text { Number of } \\
\text { Students } \\
\text { Taking the } \\
\text { Quiz }\end{array}$} & \multicolumn{3}{|c|}{ Percent Answering Question Correctly, Question on: } \\
\hline & & & & $\begin{array}{l}\text { Composite Axially- } \\
\text { Loaded Member }\end{array}$ & $\begin{array}{l}\text { Moment } \\
\text { Diagram }\end{array}$ & Combined Loading \\
\hline No & $\mid \begin{array}{c}\text { Winter or } \\
\text { Spring } 2011\end{array}$ & $\begin{array}{c}\text { Winter } \\
2012\end{array}$ & 44 & $71 \%$ & $46 \%$ & $54 \%$ \\
\hline \multirow{2}{*}{ Yes } & $\mid \begin{array}{c}\text { Winter or } \\
\text { Spring } 2012\end{array}$ & $\begin{array}{c}\text { Winter } \\
2013\end{array}$ & \multirow{2}{*}{101} & \multirow{2}{*}{$87 \%$} & \multirow{2}{*}{$51 \%$} & \multirow{2}{*}{$45 \%$} \\
\hline & $\mid \begin{array}{c}\text { Winter or } \\
\text { Spring 2013 }\end{array}$ & $\begin{array}{c}\text { Winter } \\
2014\end{array}$ & & & & \\
\hline
\end{tabular}

Figures 6, 7, 10 and 11 indicate that student performance drawing shear and moment diagrams and determining the stresses due to thermal expansion already exceeded 80 percent prior to including $\mathrm{E}^{3} \mathrm{~s}$, indicating the pedagogical methods already in place in the course were having a positive effect on student learning. Figure 7 does show a slight steady increase in student exam results on thermal expansion and a decrease in the standard deviation. Figure 11 reveals these changes were primarily for the male students as the female student average and standard deviation remained basically unchanged. The four percent increase in overall male student performance and six percent decrease in the standard deviation for the same group would indicate this $\mathrm{E}^{3}$ does have a positive effect on student short-term learning. This topic was not included on the long-term retention quiz.

The results for drawing shear and moment diagrams, seen in Figure 6, do not indicate any performance trends as there are similar exam averages and both large and small standard deviations before and after the implementation of the skateboard $\mathrm{E}^{3}$. Figure 10 shows the exam performance of female students dropped by three percent but still remained above 90 percent, which is excellent. The male students' performance was not changed but the standard deviation did drop by close to two percent. So did this $\mathrm{E}^{3}$ have any effect? In the original description of this $\mathrm{E}^{3}$, it was indicated that in addition to shear and moment diagrams, this everyday example can be used to provide a relevant illustration for bending stress, shear stress, composite beams in bending, and deflections in beams. The actual $\mathrm{E}^{3}$ described by Patterson ${ }^{17}$ is targeted at just drawing shear and moment diagrams. Expansion of this $\mathrm{E}^{3}$ to the additional course topics was a result of the interest this example sparked in the students and the engagement and questions that resulted in the classroom. Due to their own experiences, the students wanted to know why a board would break (bending stress). When shear stress was introduced and the students observed shear planes slipping in a beam model made of stacked foam beams, they asked how this related 
to the laminated materials used to build their skateboards. When the students were challenged to think of examples of composite materials, they identified skateboards with fiberglass fabric or carbon fiber layers, which led to a composite skateboard homework problem. Finally, they wanted to know why skateboards made of bamboo appeared to flex more than skateboards made of wood. This nicely introduced the idea of flexural rigidity as the calculations for deflection a bamboo and a wood skateboard were compared.

Although no conclusive gains were made in student exam performance on shear and moment diagrams to indicate improved short-term retention, the skateboard $E^{3}$ significantly improved the relevance of the topic to the students and therefore their engagement and interest. Additionally, the percent of students who could answer the conceptual question on the pop-quiz administered at least six months after completion of the Mechanics of Materials course increased by five percent, from 46 percent to 51 percent, as shown in Table 3. Student performance data specific to the additional topic areas now associated with this $\mathrm{E}^{3}$ (bending stress, shear stress, etc.) was not collected as part of this work as their inclusion in the $\mathrm{E}^{3}$ has evolved as a result of student questions.

The final $\mathrm{E}^{3}$ studied in this work was the bicycle handlebar example developed by the author to facilitate the ability to calculate stresses due to combined loading. At the end of the Spring 2012 quarter, it appeared that the $\mathrm{E}^{3}$ was not working and in fact was negatively effecting learning with the Spring 2012 class average dropping to 73.5 percent with a standard deviation of 22.5 percent. Small tweaks to the activity, including indicating they should imagine the bike is held in place on a bike rack, led to significant gains in the Winter 2013 quarter but these did not repeat in the following Spring 2013 term. The nine students who took the Spring 2013 exam in the alternative time (S2013-b) averaged only 65.6 percent with a standard deviation of 20.1 percent. The combined results of all the students shown in Figure 12 would indicate that overall the $\mathrm{E}^{3}$ had a small positive effect for female student and a slight negative effect for male students. The standard deviation increased by 3.3 percent for female students and remained unchanged at approximately twenty percent for male students after the introduction of the bicycle $\mathrm{E}^{3}$, which indicates it still needs development to be useful to the majority of students. Student comments in a voluntary survey indicated using the physical models of the bike handlebars and stems and completing the step by step activity was useful in their understanding the material. However, the student exam results do not indicate any student gains over previous methods. In addition, the results of the long-term retention quiz would indicate the use of the handlebar activity is not improving student performance and negatively effecting retention as shown in Table 3.

\section{The Effect of Everyday Examples in Engineering on Student Interest}

To help understand students' perceptions of the use of $\mathrm{E}^{3} \mathrm{~s}$ during the course, students were asked to complete an end of term, anonymous survey. One survey question asked students to rate their interest in the course material on a scale of one to five, where a one indicated a very high level of interest, a three indicated a medium level interest and a five indicated a very low level of interest. Students were also asked to indicate if the course activities improved their interest in the course with a yes or no answer. Table 4 reports the results of the student survey for students taught without $E^{3} s$ in the Spring of 2011 and students taught with $E^{3} s$ in the Winter of 2012. Thirty students took the survey in the Spring of 2011, while 77 took the survey in the Winter of 2012. 
Table 4: Percent of students indicating their interest in course material and whether or not course activities improved student interest based on 30 students surveyed in Spring of 2011 who had not received instruction using $\mathrm{E}^{3} \mathrm{~s}$ and 77 students surveyed during Winter of 2012 who had received instruction with $\mathrm{E}^{3} \mathrm{~s}$.

\begin{tabular}{|c|c|c|c|c|c|c|c|c|c|}
\hline \multirow{2}{*}{$\begin{array}{c}\text { Topics } \\
\text { Taught } \\
\text { Using } \\
E^{3 \prime s}\end{array}$} & \multirow[b]{2}{*}{ Gender } & \multicolumn{5}{|c|}{ Interest in Course Material } & \multicolumn{2}{|c|}{$\begin{array}{l}\text { Course Activities } \\
\text { Increased Interest }\end{array}$} & \multirow[b]{2}{*}{$\begin{array}{l}\text { Total } \\
\text { Count }\end{array}$} \\
\hline & & $\begin{array}{c}1- \\
\text { Very } \\
\text { High }\end{array}$ & 2 & $\begin{array}{c}3 \text { - } \\
\text { Medium }\end{array}$ & 4 & $\begin{array}{c}5- \\
\text { Very } \\
\text { Low }\end{array}$ & Yes & No & \\
\hline No & Female & $25 \%$ & $25 \%$ & $25 \%$ & $25 \%$ & $0 \%$ & $75 \%$ & $25 \%$ & 8 \\
\hline Yes & Female & $50 \%$ & $32 \%$ & $11 \%$ & $7 \%$ & $0 \%$ & $89 \%$ & $11 \%$ & 28 \\
\hline No & Male & $9 \%$ & $55 \%$ & $23 \%$ & $14 \%$ & $0 \%$ & $59 \%$ & $41 \%$ & 22 \\
\hline Yes & Male & $22 \%$ & $49 \%$ & $12 \%$ & $14 \%$ & $2 \%$ & $88 \%$ & $12 \%$ & 49 \\
\hline
\end{tabular}

Table 4 highlights the increase in student interest in the course material with the inclusion of $\mathrm{E}^{3} \mathrm{~s}$ in the course. The results for female students are dramatic with the percent of females responding Very High or High jumping from 50 percent to 82 percent. Male students started with a higher interest level, with 64 percent of male students indicating a Very High to High interest in the course prior to the introduction of $\mathrm{E}^{3} \mathrm{~s}$. This number only increased by seven percent with the use of $\mathrm{E}^{3} \mathrm{~s}$ in the course. These results would suggest relating engineering concepts to ideas students are already familiar with is more impactful for female students.

\section{Summary of Results}

The overall experience of this author using Everyday Examples in Engineering indicates the $\mathrm{E}^{3} \mathrm{~s}$ bring substantial value to the course in ways that are measurable and others that are not. Measurable gains in student learning, both long- and short-term, were observed for both male and female students with little to no difference in gains between genders. The most significant gains were seen when an $\mathrm{E}^{3}$ was used to illustrate a topic where students had previously had difficulty, which in this course was the behavior of composite materials. The earbud $\mathrm{E}^{3}$ activity used to introduce composite behavior also included the physical cable components that allowed students to develop their understanding experientially, a learning method linked to long-term retention. This activity led to an overall 25 percent increase in student exam performance and a sixteen percent increase in the students who accurately retained this material. Personal observations of the author indicate there are two main reasons this $\mathrm{E}^{3}$ was so effective:

1. Common textbook presentation of the topic, and subsequently the author's instructional approach, included examples that had little to no relevance to the students. This included the previously mentioned concrete/steel columns and the even less useful hollow metal pipes filled with a solid plug of a different metal that is used for some unknown purpose. Students were not provided with motivation to learn the material or insight to how it applied to everyday life.

2. Allowing the students to pull on a coated wire and observe the two materials deform as a unit created experiential knowledge that stayed with the students. This was far better than simply telling the students this was how composites work. This was apparent both 
during exams, when students would leave small notes on composite problems indicating it behaved "like the earbud cable", and during subsequent lessons on composite behavior in torsion and bending where students would quickly identify the kinematics of the problem required the materials to deform equally, "just like the earbud cable".

When $\mathrm{E}^{3} \mathrm{~s}$ where used to supplement the instruction for topics where student performance was already in an acceptable range, the measurable short-term results were less significant. Student exam performance for drawing shear and moment diagrams and for determining the effect of temperature changes on axially loaded members remained relatively steady with slight increases in the performance of male students and slight decreases in the performance of female students. However, the female students' exam averages for temperature effects and shear and moment diagrams remained in high 80 and low 90 percentiles, respectively. The standard deviation for these topics for female students was not affected by the use of $\mathrm{E}^{3} \mathrm{~s}$ and remained unchanged, while the standard deviation for the male students' performance was reduced by four percent for temperature changes and two percent for shear and moment diagrams. The long-term retention for moment diagram concepts was evaluated as part of this work. Although the skateboard $\mathrm{E}^{3}$ used to facilitate shear and moment diagrams did not include an activity where each student experimented with a skateboard, it referred to an everyday activity that a large percentage of the students had personal hands-on experience with and the remainder of the students had seen regularly in their day to day lives. This link to previous knowledge appears to have improved the long-term retention of moment diagram concepts, as the percent of students who accurately answered the retention quiz question on this topic increased by five percent.

Student performance in solving stresses due to combined loading prior to the implementation of $\mathrm{E}^{3} \mathrm{~s}$ was also in an acceptable range with female students averaging 85 percent and the male students averaging 80 percent on final exam questions on this topic. However, this is a topic that students work hard to understand and it was felt an $\mathrm{E}^{3}$ could improve students' overall grasp of the combined loading behavior. The bicycle handlebar $\mathrm{E}^{3}$ differed from the other $\mathrm{E}^{3} \mathrm{~s}$ studied in this work as it was the only $\mathrm{E}^{3}$ developed by the author. Although bicycles are part of students' everyday lives, handlebars that do not turn or lean when pushed on are not. This $\mathrm{E}^{3}$ resulted in the overall average of student exam performance remaining basically the same but the standard deviation increased by over three percent for female students while remaining constant at somewhat high twenty percent for male students. The results of the retention quiz illustrate that this $\mathrm{E}^{3}$ did not link students to actual previous knowledge and may have caused some confusion as the number of students who accurately answered the combined loading concept question dropped by nine percent.

These results would indicate the bicycle $\mathrm{E}^{3}$; the only one developed by the author, should either be reviewed and revised or discontinued. Considering the time and effort involved in developing this activity and in building the models, it appears it would have been a more efficient use of faculty time to first implement the proven $\mathrm{E}^{3}$ s provided on the ENGAGE website ${ }^{14}$, including those described in Patterson's ${ }^{17}$ booklets. Many of those $\mathrm{E}^{3 \text { 's }}$ also come with lesson plans, including concept development, additional example problems and suggested homework problems that allow the students to explore the topic further. 
In addition to the observed improvements in student learning and long-term material retention observed when implementing the proven $\mathrm{E}^{3} \mathrm{~s}$, student engagement was observed to increase as a result of including the Everyday Examples of Engineering in the classroom. While not measured in this work on a numeric scale, the increase in student energy in the classroom when using $\mathrm{E}^{3} \mathrm{~s}$ was both observable and measurable on a relative scale. As previously mentioned, the skateboard $\mathrm{E}^{3}$ generated numerous discussions and its use to illustrate course topics expanded well beyond its initial intent due to student interest.

This work also includes a limited measure of gains in student interest in material topics and found including $\mathrm{E}^{3} \mathrm{~s}$ improved the interest for both male and female students, with female student interest increasing significantly. This reinforces the work by others who have studied the effect of using examples that provide context to students' everyday lives and determined student interest and motivation was increased. ${ }^{18}$ As student interest has been shown to improve persistence to graduation, the significant increase in the material interest of female students is of considerable interest. Further, an interest in the material and a link to familiar ideas decreases student fear and anxiety, which improves self-efficacy. At the time of writing it is too early to determine the graduation rates of the female students in this study, but this will be reviewed in the coming years.

\section{Conclusion}

Using Everyday Examples of Engineering has been found to improve student interest and engagement in course topics, especially in female students, and to improve student learning in both the long- and short-term for both genders. As both student performance and student interest play key roles in persistence rates, the use of $\mathrm{E}^{3} \mathrm{~s}$ should be beneficial to all students. If a faculty member chooses to only introduce one or two $\mathrm{E}^{3} \mathrm{~s}$ into a course, choosing $\mathrm{E}^{3} \mathrm{~s}$ that illustrate topics that students find the most challenging will result in the greatest overall increase in student performance in the course. Everyday Examples in Engineering are also recommended for topics where students have demonstrated acceptable levels of short-term understanding, as this work found that effective $E^{3}$ s increased student long-term retention and improved student in-class engagement, a factor that improves the teaching and learning environment for everyone. This work also found that using the ENGAGE ${ }^{14}$ resource of $\mathrm{E}^{3} \mathrm{~s}$ developed and tested by other faculty is the most efficient and effective way to being using everyday examples. Although the development of new $E^{3}$ s is encouraged and can be supported by the ENGAGE group, this work illustrates that not all examples are truly within the everyday experience of the students and may not provide the hoped for results in student learning. Students are a great resource to provide $\mathrm{E}^{3}$ ideas and to truly assess the everyday nature of an idea developed by a faculty member.

\section{Acknowledgements}

The author would like to thank the NSF funded Extension Project: ENGAGE and the School of Engineering at Santa Clara University for supporting this work.

\section{Bibliography}

1. Case,R. "Gearing the demands of instruction to the development capacities o the learner", Review of educational research, 1975, 45, pgs 59-87 
2. Marek, E.A., Cowan, C.C., and Cavallo, A.M.L., "Students' Misconceptions about Diffusion: How Can They Be Eliminated", The American Biology Teacher, Vol. 56, No. 2 (Feb., 1994), pp. 74-77

3. McGowen, M.A., Tall, D.O., "Metaphor or Met-Before? The effects of previous experience on practice and theory of learning mathematics", Journal of Mathematical Behavior, Vol.29(3), 2010, pp.169-179

4. Belgaumkar, G.G., "Helping students conquer fear of math", The Hindu (English), Sept 3, 2009

5. Ross, J.A., Bradley, C.J., "Patterns of student growth in reasoning about correlational problems", Journal of Educational Psychology, Vol 85(1), Mar, 1993. pp. 49-65

6. Fryman, M.A., Quality and Process Improvement, Cengage Learning, 2002, 374 pages

7. Science of Everything: How Things Work In Our World, National Geographic, Washington D.C., 2013, 400 pages

8. Tillery, B., Physical Science, McGraw Hill, $7^{\text {th }}$ Edition, 2006

9. Prigo,R., Making Physics Fun: Key Concepts, Classroom Activities, and Everyday Examples, Grades K-8, Corwin, 2007, 240 pages

10. Townsend, D.W., Oceanography and Marine Biology, Sinauer Associates, Inc.; 2012, 512 pages

11. Munson, B.R., Young, D.F., Okiishi, T.H., Fundamentals of Fluid Mechanics, Wiley, 2006, 770 pages

12. Cengal, Y., Turner, R., Cimbala, J.M., Fundamentals of Thermal-Fluid Sciences, McGraw-Hill, 2007, 1152 pages

13. Barnett, D., Bjornsgaard, K., Electric Power Generation: A Nontechnical Guide, PennWell Books, 2000, 337 pages

14. www.engageengineering.org

15. Marra, R.M., Rodgers, K.A., Shen, D., Bogue, B., "Women Engineering Students and Self-Efficacy: A MultiYear, Multi-Institution Study of Women Engineering Student Self-Eficacy", Journal of Engineering Education, Vol 90(1), Jan, 2009, pp. 27-38

16. National Academy of Engineering, New Directions in Engineering Excellence: Keeping Students Engaged, 2009

17. Patterson, E.A. (Editor), Real Life Examples in Mechanics of Solids: Lesson Plans and Solutions, 2nd Edition, 2008, published by the Department of Mechanical Engineering, Michigan State University - available at www.engageengineering.org

18. Patterson, E.A., Campbell, P.B, Busch-Vishniac, I., and Guillaume, D.W., "The effect of context on student engagement in engineering", European Journal of Engineering Education, Vol. 36, No. 3, June 2011, 211-224 